Accepted Manuscript (AM) version of article

It is authorized for deposition in a non-commercial subject repository on acceptance of publication by the terms of the copyright.

Formatted by the author to enhance readability. 


\title{
Material Scaffolds in Numbers and Time
}

\author{
Karenleigh A. Overmann
}

\begin{abstract}
The present paper develops a framework for interpreting Upper Paleolithic artifacts from an analysis of material complexity, numeration systems, and timekeeping using cultural categorizations (Hayden \& Villeneuve, 2011), insights on the emergence of number terms in language (Menninger, 1992), and the astronomy practices of 33 contemporary hunter-gatherer societies (Yale's Electronic Human Relations Area Files World Cultures database). Key findings: (1) an absence of societies with minimal material complexity and later-stage numeration systems, suggesting that material scaffolding may be important to realizing explicit number concepts, (2) the consistency of material complexity with both early-and later-stage numeration systems, emphasizing that material complexity may precede and inform the development of complexity in numeration systems, (3) the compatibility of astronomical practices with the spectrum of complexity in material culture and numeration systems, suggesting that the awareness of time may precede both, and (4) the increasing quantification of time consistent with greater material and numeration complexity, suggesting the availability of numbers as a cognitive technology may enable the structuring of time. These findings suggest that astronomy originates in the ability to estimate and infer contextual relations among natural phenomena and transitions from these natural associations to material representations and cognitive technologies that mediate conceptual apprehensions of time as a substance that can be quantified. Given that artifacts may act as scaffolds for explicit concepts of numbers and numbers scaffold explicit concepts of time, prehistoric artifacts such as the Blombos Cave beads (ca. 75,000), Abri Blanchard and Cellier artifacts (ca. 28,000), and Taï plaque (ca. 14,000) may represent similar scaffolding and conceptual development in numbers and time. It is proposed that the prehistoric societies making these artifacts possessed, in addition to material complexity, the abilities to express quantities in language and to use material externalization and cognitive technologies. Further, the Abri Blanchard artifact is proposed to represent externalized working memory, a very modern interaction between mind and material culture.
\end{abstract}

Keywords: numerosity, numbers, time, cognitive technology, externalized memory, externalized working memory

Some 28,000 years ago, an unknown member of an Upper Paleolithic society engraved a small piece of reindeer bone, discovered in 1911 at an Aurignacian site near Sergeac, France, to represent the phases and movements of the moon (Jègues-Wolkiewiez, 2005; Marshack, 1972). The representational and quantificational feature of the artifact suggest something about its maker's material culture, the mental and behavioral capabilities underlying the artifacts made and used by a society, as well as its material complexity, a characterization of cultural complexity that emphasizes its technological aspect (Chick, 1997). Using comparative data from modern societies to form an interpretive framework, the present study suggests that the Abri Blanchard bone, the Blombos Cave beads (ca. 75,000), Abri Cellier artifact (ca. 28,000), and Taï plaque (ca. 14,000) may signify the use of cognitive technologies, concepts like numbers and time that transform the cognitive and physical environments through mechanisms of imposed structure. These artifacts also suggest that their makers used material objects to externalize both memory (i.e., the passive storage of cognitive content) and working memory (i.e., the active manipulation of cognitive content).

An interpretative framework from comparative ethnology assumes that aspects of material culture and language represent differential environmental adaptations, which in turn reveal aspects of the human cognitive capacity. In the present study, modern ethnographic observations from Yale's Electronic Human Relations Area Files (eHRAF) World Cultures database were used to examine the relationships between material complexity, number terms in language, and 
timekeeping through cultural astronomy. Greater material complexity was consistent with two cognitive adaptations: the development and use of cognitive technologies and material externalization techniques. There were two overarching results in the present study. The first was that material culture appeared to scaffold number concepts, knowledge construction that facilitates developing the rudimentary recognition of quantity known as numerosity into complex numeration systems and enabling the use of numbers as a cognitive technology. The second was that the availability of numbers as a cognitive technology appeared to provide greater complexity and structure in timekeeping as the quantificational apprehension of time.

The interpretative framework was then applied to the Blombos Cave beads, the Abri Blanchard and Abri Cellier artifacts, and the Taï plaque to characterize the societies that made them in terms of their material complexity, number systems, and use of cognitive technologies and material externalization techniques. The artifacts are consistent with modern examples of representation, quantification, material externalization, and the use of numbers and time as cognitive technologies. As a result, it is proposed that the artifacts represent material externalization, physical objects that enable previously intangible concepts such as numbers and time to be made tangible, explicit, and formalized, as well as externalized memory, physical devices used to retain and recall information and experience to enable their transmission between individuals and generations. It is proposed that the Abri Blanchard artifact also represents externalized working memory, a physical device that enables the active manipulation of information to increase its organization and apprehension and to support the attainment of a goal. Externalized working memory in particular comprises a relatively complex use of material culture to organize, manipulate, and understand cognitive content; this implies that its makers possessed fully modern cognition.

\section{Numbers and Material Culture}

The use of numbers as a cognitive technology begins with numerosity, the ability to recognize small quantities (a capability referred to as subitization or parallel individuation) and differential quantity (a capability referred to as magnitude appreciation or the analog number system) (Feingenson, Dehaene, \& Spelke, 2004; Hyde \& Spelke, 2011; Piazza, 2010). Many species, from those closely related to humans (i.e., nonhuman primates) to those fairly distant in phylogenetic terms (e.g., birds), share with humans the ability to recognize quantity (e.g., Ardila, 2010; Cantlon \& Brannon, 2006; Cantlon, Platt, \& Brannon, 2008; Dehaene, Dehaene-Lambertz, \& Cohen, 1998; Haun, Jordan, Vallortigara, \& Clayton, 2010). Ontogenetically, human numerosity has been demonstrated in infants only months old, when the influence of language and culture are minimal (e.g., Ansari, Garcia, Lucas, Hamon, \& Dhital, 2005; Carey, 2009; Cantlon, Brannon, Carter, \& Pelphrey, 2006; Feigenson et al., 2004; VanMarle \& Wynn, 2010). Cross-species sharedness and ontogenetic earliness suggest that numerosity is innate; the fact that it is found in both pre- and non-linguistic organisms suggests that quantity recognition is also largely independent of language. As an innate trait, numerosity has plausible adaptive value: The ability to recognize quantity in resources or threats enables a species to exploit the one and avoid the other (e.g., Agrillo, Dadda, \& Bisazza, 2007; Hunt, Low, \& Burns, 2008; McComb, Packer, \& Pusey, 1994).

Numerosity in Homo sapiens, however, is qualitatively different from that of other species because humans can express their innate, nonverbal sense of quantity in the material form of notches, beads, and tokens (Malafouris, 2010). This uniquely human ability may originate in the neuroanatomical integration of numerosity with cognitive abilities for directed vision and precise 
finger and object manipulation (Orban et al., 2006). Neuroanatomic integration may enable humans to express their embodied sensorimotor associations of quantity in external material phenomena — stones, bones, sticks, strings, and clay — created and modified to represent quantity (Malafouris, 2010). Thus, the confluence of abilities for precise finger and object manipulation, visual acuity, and numerosity may endow Homo sapiens with the abilities to create objects that represent number concepts and to associate those objects with the concepts they instantiate (Coolidge \& Overmann, 2012). However, it is likely that other cognitive abilities contribute to the human ability to express numbers materially, including ordinality and sequence, abstraction, and categorical representation (respectively, the cognitive abilities to organize and understand the relative position of objects and events; derive general, higher-level concepts; and associate elements through feature correspondences; see Carey, 2009; Murai, 2006; Pariyadath, Churchill, \& Eagleman, 2005; Quinn, 2011; Quinn, Westerlund, \& Nelson, 2006; Wynn, 1991).

In the human brain, the upper surface of the parietal lobe, a region known as the intraparietal sulcus (IPS), has been implicated in numerosity (Ansari, 2008; Cantlon et al., 2006; Diester \& Nieder, 2008; Fias, Lammertyn, Caessens, \& Orban, 2007; Hubbard, Piazza, Pinel, \& Dehaene, 2009; Miller, Nieder, Freedman, \& Wallis, 2003; Orban et al., 2006). The anterior part of human IPS appears to lack a homologue in the brains of old world monkeys (species of macaques), suggesting that those portions of the IPS and the cognitive functions they subserve are derived characteristics in humans (Orban et al., 2006). Imaging studies have demonstrated IPS activation during reaching, pointing, and grasping movements; saccades (fast eye movements) and attention; object matching and grasping; object size and orientation discrimination; and "by the tactile manipulation of objects, by the observation of others' hand movements, and even by the passive viewing of graspable objects, namely tools” (Culham \& Kanwisher, 2001, p. 158).

Inchoate concepts of quantity, once externalized in material form, become tangible; in becoming tangible, they also become more explicit, more manipulable, and more readily shared between individuals and generations (Malafouris, 2010, 2012). This is not to suggest that number concepts are explicit mental constructs prior to their expression in material form. Rather, it may be the act of material expression that enables the recognition of the concepts thus instantiated; key to this recognition is noticing and apprehending the similarity between a concept and its material expression (Davidson \& Noble, 1989). The recognition of similarity in turn helps solidify the mental concept, an interaction between mind and material that is dynamic, a state of "continuous reciprocal causation" (Clark, 1997, p. 171) that yields, in the case of human numerosity, greater capability and complexity in the ability to quantify. Greater capability and complexity in quantification leads to the development of numeration systems, formalized systems of quantification increased in explicitness (e.g., discrete quantities; number concepts such as ordinality and cardinality), linguistic labels (e.g., 'ten', 'million'), and lexical rules for creating new linguistic labels (e.g., 'twenty-one' from 'two', 'ten', and 'one'). In addition, material devices such as a string of beads or notches on a tally stick make intangible quantity concepts recognizable, storable, recallable, and able to be shared, thereby representing both material externalization and externalized memory.

As they develop complexity and capability, numbers become a cognitive technology, or knowledge that transforms the physical and cognitive environments through imposed organizational structures; these highlight some features of the environment relative to others, enable discrete and finer differentiations to be made, and assemble and parse information in ways that support understanding, action, and control (de Cruz, 2008, 2012). In this regard, numbers are similar to other cognitive technologies such as mapmaking and timekeeping (de Cruz, 2012; Frank, 
Everett, Fedorenko, \& Gibson, 2008; Sterelny, 2010). Arguably, cognitive technologies do not transform the cognitive environment directly; instead, they operate through mechanisms of material culture. Just as maps formalize the spatial understanding of terrain and geography to facilitate navigation and clocks and calendars facilitate the organization of time to improve the ability to plan (de Cruz, 2012), the operation of material mediation can be seen in the way beads and tally sticks enable counting and measurement to yield accuracy (i.e., the ability to reproduce a quantity's actual value), precision (the ability to reproduce a quantity's value under different conditions), and capability (the ability to instantiate large or complex numbers) in quantification. The Homo lineage has a long history of adapting to its environment by externalizing concepts in material form, creating cognitive technologies that mediate the perception, understanding, and engagement of the environment (Gowlett, 1984).

\section{The Prehistory of Number Concepts}

Quantification may have begun with the recognition of correspondences between fingers or objects and quantities (Rouillon, 2006). Quantification through correspondence can be nonverbal: For example, the bead-prayer correspondence in a rosary requires neither language nor concepts for numbers. d'Errico (1998) notes the challenge inherent in demonstrating that prehistoric beads were used in a rosary-like fashion, but ethnographically, the use of beads for both personal ornamentation and counting often coincide. That the string of beads was a likely material scaffold for realizing explicit number concepts from antecedents of numerosity is suggested by their unique utility (i.e., their capacity for instantiating a number line, ordinality, etc.), ubiquity (beads are found at nearly 30 MSA sites that span, at a conservative estimate, 40,000 years and 4,000 miles; see Wynn, Overmann, Coolidge, \& Janulis, 2012), and social value (their tendency to be counted because of the effort needed to produce them). In the sample of societies considered in the present analysis, beads used as personal ornamentation were found in societies with simpler and complex material culture, as well as with early- and later-stage numeration systems. However, only materially complex cultures used beads for quantification. Such devices appear to precede the emergence of explicit number concepts (consistent with the idea that they can act as scaffolds) but do not guarantee that emergence (consistent with the idea that individuals and societies can react differently to similar conditions).

Fingers likely preceded material devices like beads, and finger-counting may extend to 27,000 years ago if Rouillon (2006) is correct that the pattern of finger lengths in the negative handprints at Cosquer cave represents finger-signs for integers. The role of fingers in expressing quantity concepts, either directly or in material form, is supported by their cognitive prepotence (likely a function of the shared neural substrate for numerosity and precise motor control of the fingers) and cross-cultural ubiquity (a prevalence that suggests a neural basis; see Andres, Di Luca, \& Pesenti, 2008; Orban et al., 2006; Rips, Bloomfield, \& Asmuth, 2008; Tang et al., 2006). Finger and hand movements play an important role in the mastery of counting and simple arithmetic: Motor-evoked potentials for the muscles of the right hand increase during small numbers judgments (i.e., numbers consistent with subitization; see Sato, Cattaneo, Rizzolatti, \& Gallese, 2007), hand movements unrelated to counting can disrupt the ability to count (Imbo, Vandierendonck, \& Fias, 2011), and hand movements related to counting can facilitate learning to count and performing simple arithmetic (Domahs, Moeller, Huber, Willmes, \& Nuerk, 2010; Klein, Moeller, Willmes, Nuerk, \& Domahs, 2011). The close association of number processing, finger movements, and directed vision has also been demonstrated in fMRI studies of children performing number and visual tasks (Krinzinger et al., 2011). 
Using the fingers to count is a trait shared across cultures; further, in the present study, finger-counting persisted despite increases in the complexity of material culture and numeration systems. This persistence reflects the usefulness of fingers for both learning to count (e.g., Crollen, Seron, \& Noël, 2011) and performance of simple arithmetic, and it is possibly a result of the neural interrelation between numerosity and precise manipulation of the fingers. Culture can also influence the specific expression of numbers by the fingers: Neural connections develop under the influence of practice, a culturally mediated mechanism that gives rise to phenomena such as the differential cross-hand reaction times noted in Chinese and German finger-counting (Domahs et al., 2010). In the German culture, people count to five on a single hand, demonstrating an increased reaction time when counting to six involves the other hand; in comparison, Chinese people count to nine on a single hand, and cross-hand reaction time increases when counting to 10 requires the other hand (Domahs et al.).

As quantification devices, however, fingers are limited: Material devices such as stringed beads, knotted strings, and tally sticks enable quantities to be counted and calculated with an accuracy, precision, capacity, and persistence that fingers (no matter how neurally interrelated or cognitively prepotent) simply cannot provide, even when supplemented by toes and other body parts. At some point, a material device such as a string of beads may be recognized as counting, instantiating a number line, or indicating higher quantities. Material artifacts capable of instantiating number concepts and repurposing the cognitive system for numbers may have been available for at least 30,000 and possibly as many as 100,000 years. Examples include the Blombos Cave beads (ca. 75,000; Fig. 1; see d'Errico, Henshilwood, Vanhaeren, \& van Niekerk, 2005), which may have enabled correspondence quantification or, more provocatively, have acted as a material scaffold for the indication of higher quantities (Overmann, Wynn, \& Coolidge, 2011; Wynn et al., 2012). The Abri Cellier bones (ca. 28,000; Fig. 2) and Taï plaque (ca. 14,000; Fig. 3) are notched in a manner that appears both deliberate and unrelated to butchery; the notches may represent tally notations, the Abri Cellier artifact indicating a lesser quantity, the Taï plaque a greater one (Marshack, 1991).

As in finger-counting, the use of material devices can restructure the brain: Neural connections are formed under the influence of deliberate practice as proficiency is acquired (de Cruz, 2008, 2012). Similar to evidence that practice in reading increases both white matter density and interhemispheric connectivity and that practice in spatial navigation increases gray matter, practice in arithmetic appears to change the relative contribution of different brain regions (Carreiras et al., 2009; de Cruz, 2012; Maguire, Woollett, \& Spiers, 2006; Tang et al., 2006; Zamarian, Ischebeck, \& Delazer, 2009). Cultural learning (a phenotypic change) also results in behavioral change, and behavior can interact with the environment in ways that enhance or degrade fitness. Since natural selection favors adaptive phenotypes and their genetic bases, over time, this might yield a dedicated neural substrate for what was originally a cultural acquisition (see Wynn et al., 2012, for a review of gene-culture co-evolutionary models).

However, rather than modifying the underlying cognitive ability, cultural acquisitions can simply map onto neural circuitry with compatible functionality and sufficient plasticity to support them (i.e., neuronal recycling; see Dehaene \& Cohen, 2007). For example, in reading, the brain maps visual inputs onto the lateral occipito-temporal junction, a location that is constant "across individuals, cultures, languages, and orthographic systems” (Wynn et al., 2012, p. 15). The neuronal origins remain evident in the functional constraints that govern the co-opting cultural 


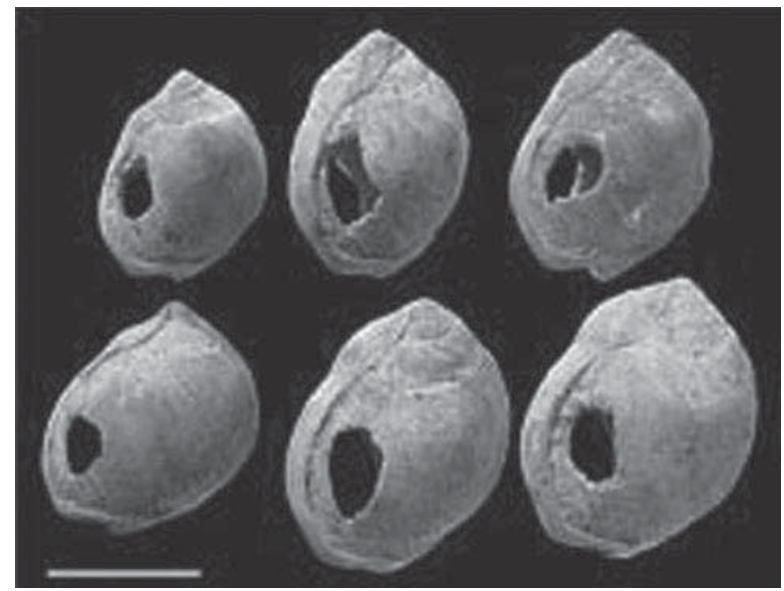

Fig. 1. Six of the Blombos Cave beads (ca. 75,000). Once strung, they may have formed an early quantification device (similar to the modern rosary), permitting one-to-one correspondences and instantiating numeric concepts such as the number line and ordinality. More provocatively, they may have helped to scaffold higher numbers (i.e., to the number of beads on the string).

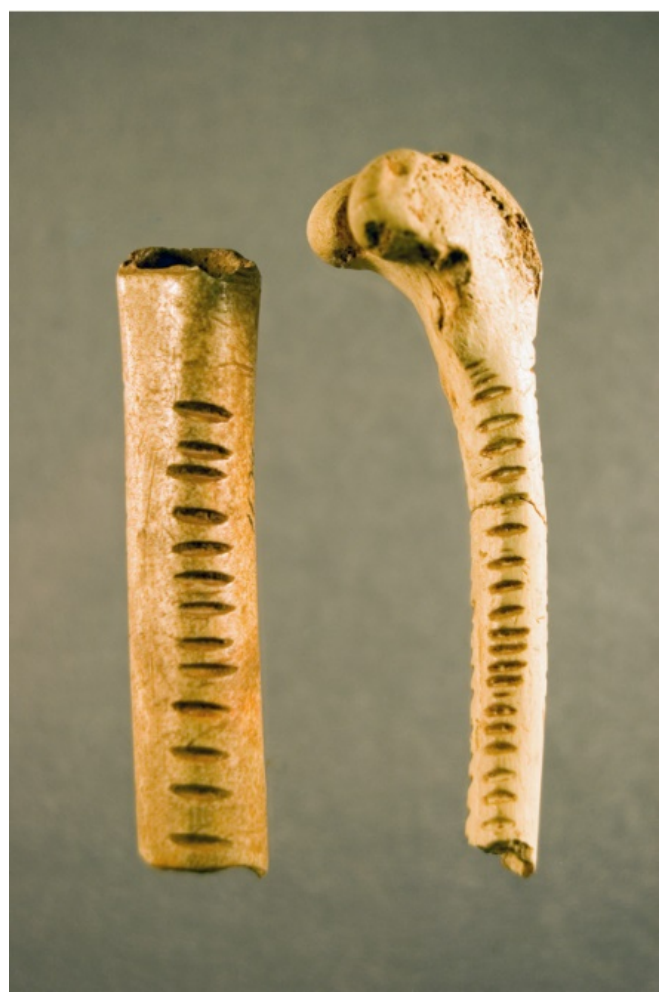

Fig. 2. The Abri Cellier artifact (ca. 28,000); the notches might have represented quantity notations.

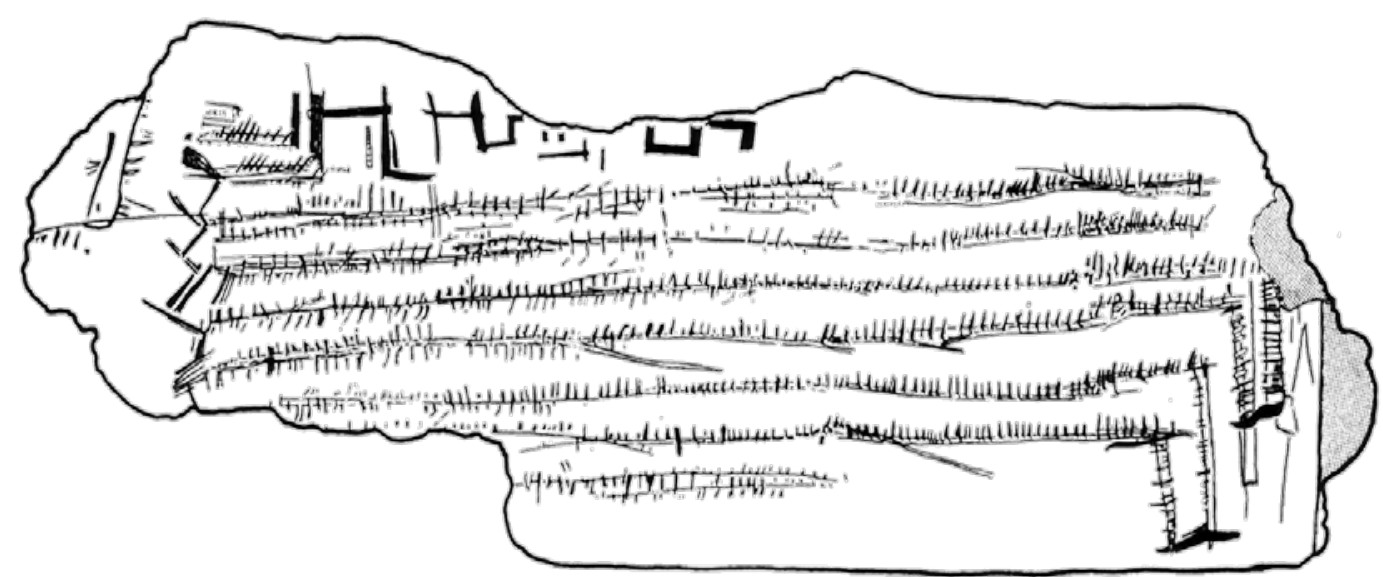

Fig. 3. The Taï plaque (ca. 14,000); the incised marks may have represented quantity to a relatively high number (Marshack, 1991).

acquisition (Dehaene \& Cohen), seen in reading as limitations in the complexity of orthographic characters that can be parsed (Wynn et al.) and in numerosity as Weber's law of just-noticeable differences and limitations of attentional resources that together form the subitization constraint, the component of numerosity enabling the rapid, unambiguous recognition of quantities only up to three or four (Burr, Turi, \& Anobile, 2010; Piazza, 2010; Pica, Lemer, Izard, \& Dehaene, 2004). 
Material scaffolding (e.g., moving beads along a string) may help to escape the subitization constraint, which appears to predominate in the initial expression of number concepts (but see Piazza, 2010), as evidenced by the way in which number terms emerge in language.

As they emerge, number terms appear to transition through two universal stages that reflect the level of enrichment and capability in the underlying numeration system. The early stage of number-term emergence produces only limited and inexact quantities (i.e., 'one', 'two', and 'many'), consistent with subitization (Menninger, 1992). Material scaffolding - counting a string of beads, for example - may facilitate the conceptual 'leap' that first transcends the subitization constraint and then makes higher quantities accessible (Malafouris, 2012; Menninger, 1992; Overmann et al., 2011; Wynn et al., 2012). Hurford (2007) suggests the scaffolding is also linguistic: "Without using language, we still can't go [higher than the subitizing range of about four]" (pp. 91-92), though arguably linguistic scaffolding is more applicable to quantities that exceed the subitizing range. In comparison, the later stage of number-term emergence produces numbers in the hundreds, thousands, or more with accuracy and precision, expanding the need for linguistic labels and lexical rules to create new number terms (Menninger, 1992) and reflecting the use of material externalization and externalized memory (e.g., counting beads on strings or notations on tally sticks). At some point, material scaffolds for large numbers become infeasible (e.g., manually counting to hundreds of thousands), suggesting that large numbers become apprehended as linguistically (rather than materially) scaffolded concepts, though material devices may still be used to record and manipulate them.

From the way in which number terms emerge from material and linguistic scaffolds, the present study predicted that later-stage numbers would be found in conjunction with material complexity and that early-stage numbers would be found with material simplicity. In general, this is what was found. In addition, there were no cases of material simplicity with later-stage numbers, and there were lags between material complexity and numeration complexity; this was interpreted as material complexity at least partially informing numeration complexity.

\section{Material Culture and the Development and Enrichment of Numeration Systems}

To investigate the relationship between material complexity and the development of numeration systems, Hayden and Villeneuve's characterizations of cultural complexity were used. These authors classified 82 societies from Africa, Asia, Europe, North and South America, and Australia as "simpler" or “complex" based on characteristics of population density, mobility, property ownership, food storage, socioeconomic stratification, trade, surpluses and associated social activities, and indications of emerging social stratification and religion (pp. 334-335; the term 'material complexity' is used herein to highlight the technological aspect of cultural complexity, though social valuation of material possessions and investment of resources are also important; see also Chick, 1997 and Owens \& Hayden, 1997 for discussions of measures, issues, and validity in cultural complexity, including the interrelationship between mental, behavioral, and material [or artifactual] aspects of culture). Notably, though Hayden and Villeneuve listed numeration systems as a classification criterion, this was not a significant factor in classifying material culture as simple or complex (Hayden, personal communication); accordingly, the present analysis excluded the numeration systems criterion as a determinant of material complexity on grounds of circularity.

Of the 82 societies considered by Hayden and Villeneuve (2011), there were 33 for whom sufficient data were available in Yale's eHRAF database to characterize their numeration system 
complexity (Table 1 lists the societies considered in the present analysis and their geographic distribution; Table 2 contains the four categories created by the conjunction of material complexity and number-term emergence and the distribution of societies within the categories). For each of these 33 societies, the eHRAF database contained between one and seven ethnographies (with an average of two per society) containing observations on which to base a categorization of the numeration system as early or later stage using Menninger’s (1992) two-stage framework.

Table 1. Geographic Distribution of Societies Included in the Study

\begin{tabular}{|c|c|c|c|}
\hline Region & Sub-region & Group & Society \\
\hline \multirow{2}{*}{ Africa } & East & 1 & Mbuti \\
\hline & South-central & 1 & San \\
\hline \multirow{4}{*}{ Asia } & East & 2 & Ainu \\
\hline & \multirow{2}{*}{ Northern } & 2 & Chukchi \\
\hline & & 3 & Koryaks, Yakut \\
\hline & Southeast & 1 & Andamans, Semang \\
\hline \multirow{2}{*}{ Australia } & Central & 1 & Aranda \\
\hline & Northern (Islands) & 2 & Tiwi \\
\hline Europe & Northeastern & 2 & Saami \\
\hline \multirow{8}{*}{$\begin{array}{l}\text { North } \\
\text { America }\end{array}$} & California & 3 & $\begin{array}{l}\text { Chimaríko, Klamath, Maidu, Pomo, Shasta, } \\
\text { Wintu, Yokuts, Yuki, Yurok }\end{array}$ \\
\hline & \multirow{2}{*}{ Central } & 2 & Ojibwa \\
\hline & & 3 & Assiniboine, Chipewyan \\
\hline & Eastern & 2 & Innu \\
\hline & \multirow{2}{*}{ Northern } & 2 & Alutiiq, Inuit \\
\hline & & 3 & Aleut \\
\hline & Northwest Coast & 3 & Quinault, Tlingit \\
\hline & Northwest Interior & 3 & Sahaptin \\
\hline \multirow{2}{*}{$\begin{array}{l}\text { South } \\
\text { America }\end{array}$} & Southern & 2 & Tehuelche \\
\hline & Tierra del Fuego & 1 & Ona, Yahgan \\
\hline
\end{tabular}

Note. Group 1 reflects societies categorized as materially simple with early-stage numeration systems, Group 2 materially complex with early-stage numeration systems, and Group 3 materially complex with later-stage numeration systems (see Table 2). Interestingly, in the seven sub-regions with two or more societies (northern and southeast Asia, California, northern and central North America, the Northwest Coast of North America, and Tierra del Fuego), classifications either fell into one group (e.g., the nine societies in California all fell into Group 3) or into two groups that differed only by one factor (i.e., material complexity or numeration system complexity but not both). This geographic consistency was interpreted as reflecting factors of common ancestry, social interaction, and shared environmental challenges, and the cultural affinity in turn implied that the categorization of material and numeration complexity, performed independently of geographic proximity considerations, was reliable. The cultural affinity also suggested that the data were not independent, a circumstance in cross-cultural studies known as Galton's problem, a factor that will be controlled in follow-on studies (Hendrix, 1997; Schaefer, 1974).

Simple material culture and early-stage number terms (Group 1). Material simplicity (Hayden \& Villeneuve, 2011) was consistent with the early stage of number term emergence. The societies in this group (hereafter referred to as Group 1; see Table 2) were likely to use the term 'many' to indicate quantities near or slightly higher than the subitization constraint, or to count in pairs (a correspondence method of quantification). The Mbuti, for example, used the term 'many' to indicate quantities higher than four or five and counted in pairs (Turnbull, 1965, 1983). The Andamanese at times depicted quantities with only two categories, either as 'small' or 'big' (Cipriani \& Tayler, 1966), and they lacked terms for numbers higher than six (Man, 1932). The 
Aranda counted 'many' after reaching 'four' (Spencer \& Gillen, 1927). Observers also noted a general lack of skill, interest, or both in characterizing and communicating larger quantities, as well as an absence of vocabulary with which to indicate higher quantities (i.e., these languages lacked terms analogous to 'tens', 'hundreds', or 'thousands' in English).

Table 2. Intersections of Material Complexity and Numeration Systems.

\begin{tabular}{ll}
\hline $\begin{array}{l}\text { Early Number Stage (Group 1) } \\
\text { Andamans, Aranda, Mbuti, Ona, } \\
\text { San, Semang, Yahgan }\end{array}$ & $\begin{array}{l}\text { Simple Hunting-Gathering Societies } \\
\text { Later Number Stage }\end{array}$ \\
$\begin{array}{ll}\text { Early Number Stage (Group 2) } \\
\begin{array}{l}\text { Ainu, Alutiiq, Chukchi, Innu, Inuit, } \\
\text { Ojibwa, Saami, Tehuelche, Tiwi }\end{array}\end{array}$ & $\begin{array}{l}\text { Complex Hunting-Gathering Societies } \\
\text { Later Number Stage (Group 3) }\end{array}$ \\
& $\begin{array}{l}\text { Aleut, Assiniboine, Chimaríko, Chipewyan, Klamath, } \\
\text { Koryaks, Maidu, Pomo, Quinault, Sahaptin, Shasta, Tlingit, }\end{array}$ \\
\hline
\end{tabular}

Note. Classification of 33 modern hunter-gatherer societies in terms of material complexity (Hayden \& Villeneuve, 2011) and number term emergence in language (after Menninger, 1992). The sample was evenly split between material simplicity $(n=16)$ and material complexity $(n=17)$, yet the difference in the prevalence rate of the early or later stages of number term development was significantly, $\chi 2(1, N=33)=9.44, p=.002$, two-tailed, Cohen's $w=.53$, a large effect; when the small sample size was corrected, $\chi 2(1, N=33)=7.00, p=.008$, two-tailed, Cohen's $w=.46$, a medium-tolarge effect. There were no instances of a materially simple society with the later stage of numbers, and for materially complex societies the prevalence of later stage numbers was twice that of early stage numbers. The classification of the Andamans, Aranda, Ona, Mbuti, and Yahgan in Group 1, the Inuit, Tehuelche, and Tiwi in Group 2, and Tlingit, Yakut, and Yokuts in Group 3 agree with Divale's (1999) classifications, which were based on the highest number counted and the degree of food storage. Divale's analysis would also have placed the Koryak and Klamath in Group 2, though Group 3 appears more appropriate. Divale underestimated the Koryak's highest number counted, showing them counting no higher than 101; this is contradicted by Jochelson's (1905-1908) observation of the Koryak counting to 1,000. Divale may have similarly underestimated the Klamath's ability to count to high numbers; Spier (1930) noted their use of lexical rules to form number terms, suggesting an ability to count higher than the 101 noted by Divale.

Several observers of Group 1 also noted a lack of material possessions for which number concepts would have been needed. For example, Gusinde (1931) observed of the Ona (also known as the Selk'nam), "Proceeding from their extremely limited property in material cultural goods, one expects from the outset only a limited development of counting and the number system" (p. 1580). Gusinde and Schütze (1937) said of the Yahgan, “Their material possessions are amazingly meager. Hence they can do without numbers even more easily than without a complicated scale of value” (p. 1383). The material culture and numeration system of the Amazonian Pirahã, a society renowned for material simplicity and a lack of numbers (perhaps paradigmatically so; see Everett, 2005, 2008), might fit this category as well. The association of minimal material culture and earlystage numeration systems highlights the potential importance of material scaffolding for the development of explicit number concepts, an insight that might be summed up as follows: With little material culture, few number concepts.

Complex material culture and later-stage number terms (Group 3). In comparison, many of the societies designated by Hayden and Villeneuve (2011) as materially complex were in the later stage of number term emergence (hereafter Group 3; see Table 2). Group 3 societies used material devices such as tally sticks or beads for counting; they were also likely to have a more formal system of numbers with one or two bases (five and 20 were common) and to form higher 
numbers through the combined application of material devices and linguistic lexicalization rules. Counting into the hundreds and in some cases to infinite quantities was observed. The Tlingit, for example, had a quinary (base five) system, formed higher numbers with lexicalization rules, and counted ordinally into the hundreds (Emmons \& de Laguna, 1991). The Chimaríko, Sahaptin, Shasta, and Yuki possessed a method of counting based on the number five, the Klamath a numeration system including both quinary and decimal concepts, and the Wintu a numeration system based on base 10 (Gatschet, 1890; Spier, 1930).. The Chukchi (or Chukchee) developed a numeration system with two bases, quinary and vigesimal (base 20) (Antropova \& Kuznetsova, 1964; Bogoraz-Tan, 1904-1909). Group 3 societies also used material devices for quantification: For example, the Pomo used stringed beads and tally sticks of various sizes, with a small stick equivalent to 80 beads and five tallies "equivalent to one of the large sticks or four hundred beads" (Barrett, 1952, p. 507). Quantification proficiency was not universal, however, as the counting ability of the Chukchi was described as minimal or, in some individuals, absent (Jochelson, 19051908), an unevenness of knowledge perhaps indicative of an emerging cultural development.

Complex material culture and early-stage number terms (Group 2). Some of the materially complex cultures had early-stage numeration systems (hereafter Group 2; see Table 2). The lag suggested that material complexity precedes the transition of numeration systems from the early to the later stage and perhaps positions the first as a necessary precondition for the second. Further, there were no instances of societies with material simplicity and later-stage numeration systems, a finding consistent with the idea that greater complexity in material culture and social organization work to enrich numeration systems. Material culture, for example, provides the stringed beads that can instantiate higher quantities, as well as the social valuation inherent in reasons for counting the beads. Social requirements can also necessitate quantification: Both the Ainu and Korak were described being cheated in trade through a disadvantage in quantification skills, implying both an awareness of the disadvantage and a possible inspiration to overcome it (Jochelson, 1905-1908; Takakura \& Harrison, 1960). In the process, individuals with number concepts understand the world in new ways, developing cognitively under the influences of exposure to the knowledge of explicit numbers and the practice of quantification.

Material possessions and counting. Not all aspects of material culture may be equally effective in scaffolding the development of numeration systems. Instead, some material possessions seem more likely to engender quantification because of their significance in socially important processes (e.g., their utility in ensuring the availability of resources supporting the group's survival, as argued by Divale [1999], as well as their value in trade or ritual or their cost in terms of the labor needed to create them). Beads, for example, are material possessions whose production entails a specific and somewhat specialized investment of labor, with the result that they acquire social value that makes them more likely to be counted. This was exemplified by the Pomo, who counted beads when giving them as gifts, paying them as wages, or using them for such purposes as ritual sacrifices, sealing treaties, or settling blood feuds (Barrett, 1952). Thus, it may be material possessions with a specific social value, rather than material possessions in general, that inspire the need to quantify them to higher numbers, with greater accuracy and precision, and in ways that are more explicit and formal, thereby enriching systems of numeration. In this sense, greater enrichment in numeration systems also implies the development of systems of social value.

Simply, when it comes to counting, all material possessions are not equal: Those that are counted have some kind of social importance, value, or usefulness, as demonstrated by the range of domains in which numbers are employed: 
- survival and economy (the Saami [Group 2] count reindeer; see Anderson, 1978; Bernatzik \& Ogilvie, 1938);

- wealth and prestige (the Pomo [Group 3] count beads; see Barrett, 1952);

- $\quad$ trade (e.g., the Saami; see Itkonen, Guemati, \& Perez-Roman, 1948);

- gambling (e.g., the Mbuti [Group 1], Tlingit, and Yokuts [both Group 3]; see Emmons \& de Laguna, 1991; Gayton, 1948; Turnbull, 1965);

- basket-making (the Yokuts; see Buckley, 1982; Latta, 1949);

- rituals (the Aleut, Pomo, and Yurok [all Group 3]; see Aginsky, 1939; Alexander, 1949; Pilling, 1978); and

- time (e.g., the San [Group 1], Saami [Group 2], and Pomo [Group 3]; see Anderson, 1978; Barrett, 1952; Loeb, 1926; Silberbauer, 1981).

The idea that material complexity and social value act together to enrich numeration systems is similar to (but broader than) the hypothesis offered by Divale (1999), who suggested that climatic instability caused the need to store food, necessitating the counting of seeds and other foodstuffs and leading to the development of numeration systems (arguably, given the wide variety of employments to which numbers are applied, there was more fueling the hominin environmental adaptation than extreme weather and the desire not to starve, though these incentives undoubtedly headed the list).

In general, the numeration systems of Groups 2 and 3 were more explicit and well developed than those of Group 1. This pattern, however, was not unequivocal, for several reasons. First, the emergence of number terms in any language may not be a simple two-stage transition but one that consists of multiple stages, sub-stages, and significant variation, complicating the categorization of any particular numeration system as early- or later-stage. Second, the number of societies supporting material and number complexity categorizations was small (i.e., only 33 societies) and the ethnographic observations unlikely to have been comprehensive. Finally, some of the ethnographies predated the theoretical and methodological advances realized by anthropology as a discipline over the last century, with a concomitant lack of training and experience on the part of nineteenth-century ethnographers. However, against these factors must be set the fact that continued historical contact alters the cultural practices of previously isolated peoples, including their numeration systems, increasing the value of initial- and early-contact ethnographies.

\section{The Blombos Beads, Abri Cellier Artifact, and Taï Plaque in Context}

When the Blombos Cave beads (ca. 75,000; Fig. 1), Abri Cellier bones (ca. 28,000; Fig. 2) and Taï plaque (ca. 14,000; Fig. 3) were considered in terms of the framework of material and numeration complexity developed in this analysis, the objects bore notable similarities to the strings of beads and tally notations used for quantification purposes by modern hunter-gatherer societies, something that has been previously pointed out, especially for the Cellier and Taï artifacts (e.g., Marshack, 1985, 1991; Mithen, 1996). This is a provocative interpretation of the Blombos Cave beads (Overmann et al., 2011) because their antiquity implies that modern cognition may reach a greater time depth than is commonly held, though the suggestion is consistent with the interpretation of Middle Stone Age cultural and cognitive complexity by McBrearty \& Brooks (2000); it is less provocative for the Cellier and Taï artifacts because the cognitive capabilities of Upper Paleolithic societies are frequently considered modern in essential respects. 
The notches on the Abri Cellier bone appear deliberate, not inadvertent as the haphazard byproduct of butchery would appear (Marshack, 1991), suggesting their intent was the externalization of cognitive content (de Cruz, 2004), perhaps for quantification purposes similar to those expressed by the notations on modern tally sticks and similar devices. The idea that the Cellier artifact represents quantification is unsurprising, given that its archaeological context contains cave art (Conneller, 2011), exotic raw materials used to produce blades (Woods, 2011), beads and ornaments made of teeth, shells, and ivory, and regional differences suggestive of cultural variation (Vanhaeren \& d'Errico, 2006), all of which imply significant cultural complexity. That complexity would certainly be consistent with the complexity implied by the Abri Blanchard device (ca. 28,000; see Jègues-Wolkiewiez, 2005) and Cosquer Cave number-sign handprints (ca. 27,000; see Rouillon, 2006), evoking the distribution of complexity seen in the current sample (i.e., material and numeration complexity was similar for groups with geographic proximity, a finding interpreted as reflecting factors of common ancestry, social interaction, and shared environmental challenges; see Table 1).

The organization of marks into groups, such as those seen on the Taï artifact, reinforces the impression of an intent to represent numbers (de Cruz, 2004; Marshack, 1972, 1985, 1991). d'Errico and colleagues (d'Errico, 1991; d'Errico et al., 2003) have noted that some of the Taï marks appear compressed, a disposition across the surface of the artifact that suggests their totality was unplanned, indicating temporal separation in their accumulation that would be consistent with quantification (d'Errico, 1998). If the marks do not specifically represent a calendrical notation, as Marshack (1991) has suggested, their grouping is nonetheless consistent with the way in which number concepts have been shown to develop, which is in an overall progression from ordering to grouping and grouped groupings (Coolidge \& Overmann, 2012; Menninger, 1992). Moreover, the use of material devices for quantification by modern societies occurs in Groups 2 and 3 (i.e., in conjunction with material complexity), suggesting that the Upper Paleolithic societies who produced the Taï and Cellier artifacts were also materially complex and that if they had only early terms for numbers, they might well have been on their way to developing greater complexity in numbers, given the availability of material devices with which to scaffold them.

\section{Numbers, Material Culture, and Time}

Time is a system of relations among events or occurrences (Dowden, 2011), a cultural notion constructed through practices that estimate or quantify 'time' in, for example, daily or annual amounts. Time is conceptualized in terms of motion (i.e., who moves, the perceiver or time), direction (linearly or circularly), pace (fast or slow), frame of reference (whether event sequencing or temporal ordering is ego-centric or absolute), and duration (quantified through experiential associations or numbers). There is an extensive literature on the first four characteristics, particularly in metaphor and development (e.g., Boroditsky, 2000; Casasanto \& Boroditsky, 2008; Gentner, 2001; Kamii \& Russell, 2010; Torralbo, Santiago, \& Lupiáñez, 2006); the final characteristic, duration, was the focus of the present study.

The societies in the sample estimate or quantify time through practices of cultural astronomy (i.e., by monitoring or counting appearances, positions, or movements of the sun, moon, and stars). These practices were observed in societies with both simple and complex material culture and with both early- and later-stage number terms. The consistency of cultural astronomy with the spectrum of material and numeration complexity suggests that the subjective awareness 
of time (see de Smedt \& de Cruz, 2011, for a review of the cognitive bases of the sense of time) may precede both material culture and the development of numbers, and that timekeeping may originate in innate cognitive abilities for estimating and inferring contextual relations among natural phenomena. With increased material and numeration complexity, however, timekeeping transitions from these relational estimations to techniques of material externalization and the use of cognitive technologies. In particular, the use of numbers as a cognitive technology enables the abstract concept 'time' to be made more explicit and to be conceptualized in terms of material and quantificational representations (i.e., counting the appearances of the moon with knotted strings). In the process, numbers provide a scaffolding effect for time similar to the scaffolding effect that mind-material interaction supplies for numbers.

Timekeeping can be characterized as the recognition of correspondences between two things, such as the height of the stars above the horizon and the present time of night or year. The two things in the relationship of correspondence are 'time', an abstract concept, and some physical representation of time, a materially realized and thus more concrete concept. Timekeeping can also be characterized as quantification: for example, in counting moons and partial moons (i.e., lunar cycles and phases) in order to describe years and partial years, through material techniques like notched sticks or knotted strings that represent discrete quantities of time. The material realizer might occur naturally, as the height of the sun used to estimate the approximate time of day. The material realizer might also be a manufactured representation, such as knots in strings or an artifact such as that found at Abri Blanchard, whose incised shapes suggest lunar phases and whose overall pattern of marks trace the moon's azimuthal positions over a period of several months (Fig. 4; see Jègues-Wolkiewiez, 2005).
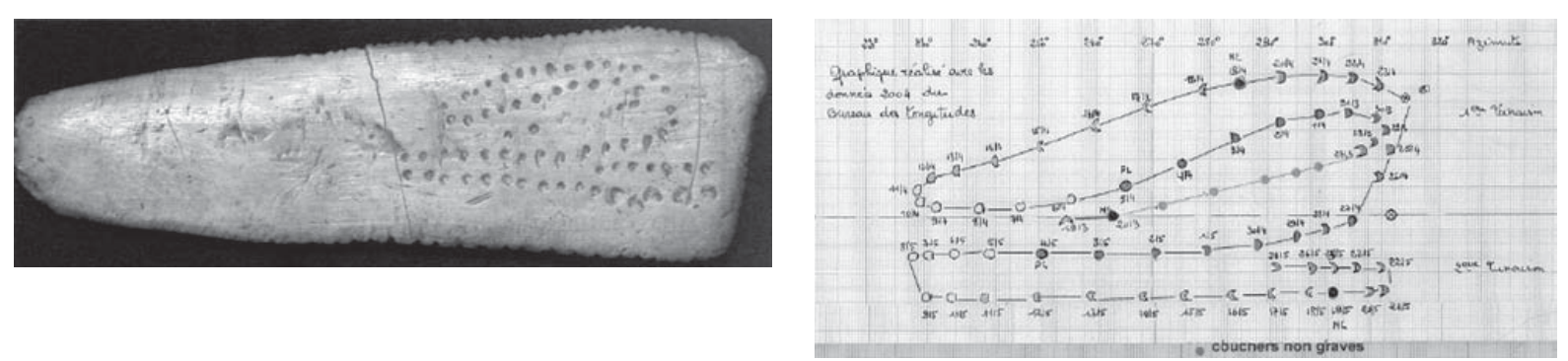

Fig. 4. Left: The Abri Blanchard artifact (ca. 28,000) represents lunar phases and analemma, the serpentine figure created by the moon's successive azimuths and zeniths (respectively, the moon's positions of rising and setting on the horizon and nightly maximum height in the sky; see Jègues-Wolkiewiez, 2005; Marshack, 1972). Right (from Jègues-Wolkiewiez, 2005): Once finished, the representations would have enabled the artifact's possessor to make one-to-one correspondences between the artifactual and lunar positions. The representations would have helped whoever made the artifact to understand the lunar sequence and cycle of appearances and movements, acting as externalized working memory in helping to organize and manipulate cognitive content. Significantly, the artifact appears to be a finished product, implying there were earlier rough drafts that helped create it.

\section{Factors Governing Relational Estimations of Time}

As modern hunter-gatherers are, prehistoric societies were probably intimately familiar with the sun, moon, and stars. The ability to assess whether they named these phenomena, told stories to explain them, or used relational estimation techniques or quantification is indirect (since such things do not preserve) but might be inferred from a comparison of their material artifacts with 
similar devices used in modern societies. Using the sun, moon, and stars for timekeeping, however, is complicated by factors that enhance or inhibit the apprehension and usability of their patterns (i.e., predictability, which is a function of recurrence and regularity; variability, which constrains pattern apprehension and usability; and accessibility, functions of terrain and weather that impact observation). These factors act to limit what is initially possible in timekeeping.

The sun's diurnal pattern is easy to use for an approximate time of day, and variations in day length (in conjunction with other seasonal change) can be used to establish the approximate time of year, recurrence that is highly predictable and accessible. The incremental subtlety of the sun's day-to-day variation, however, means that use of the pattern for keeping track of intermediate amounts of time (e.g., monthly or weekly) is difficult without material support. The stellar progression similarly enables diurnal and annual timekeeping, but the latter necessitates remembering the pattern of star recurrence from year to year (Kelley \& Milone, 2005). Rising stars can be used to estimate the month (and perhaps even the week), but only if the stellar pattern is remembered in detail and viewed from a similar horizon (i.e., the same stars rise earlier in the plains than in the mountains). The most recognizable patterns of the moon are its recurrence (the sidereal month of 27.0 days) and succession of phases (the synodic month of 29.5 days) (JèguesWolkiewiez, 2005), both of which can be used to estimate months and partial months.

Since these factors limit the range of timekeeping possible without material support, a paucity of material devices or numbers restricts timekeeping to techniques that work within the range (i.e., relational estimations, which use things like the height of the sun in the sky to estimate an approximate time of day). Relational estimation entails apprehending the significance of relationships among natural phenomena and may relate to the core domain of causality posited by Carey (2009) as an innate representational resource for contextual and relational knowledge. Relational estimation may also involve specific perceptual input analyzers, such as the cognitive ability for drawing inferences from shadows. Shadows can be used to estimate the time of day or year; further, if closely measured from a constant position, shadows can also enable detection of the solstices, the longest and shortest days of the year. Shadow perception is neurally configured to 'assume' things like there being a single, stationary light source located 'above' the viewer's retinal coordinates (Kleffner \& Ramachandran, 1992; Mamassian \& Goutcher, 2001; Tarr, Kersten, \& Bülthoff, 1998) to enable extraction of contextual inferences about the object casting the shadow (i.e., its depth, shape, location, background, movement, and trajectory; see Cavanagh \& Leclerc, 1989; Kender \& Smith, 1987; Kersten, Mamassian, \& Knill, 1997; Mamassian, Knill, \& Kersten, 1998; Ramachandran, 1988; Sun \& Perona, 1995), as well as the movement and direction of the light source (e.g., Knill, Mamassian, \& Kersten, 1997; Mamassian, 2004).

The perceptual assumptions associated with shadows and the ability to infer contextual relations from them are shared across species, including nonhuman primates and human infants (e.g., Imura et al., 2006; Imura, Tomonaga, \& Yagi, 2006). The cognitive basis for inferring contextual relations from shadows seems logically extensible to other relational estimation techniques used for time (e.g., sunbeam movement, sun height, lunar phases, or the appearance of spring, though their specific cognitive bases have not yet been established). Because shadow and other cause-effect inferences are innate, the present study predicted their use would prevail in conditions of little material culture and early-stage numbers and would diminish as material culture and numbers became available and relied upon to mediate cognitive understandings of the environment. In broad terms, this is what was found. 


\section{Material Devices in the Quantification of Time}

Once they are available, material devices enable the quantification of time to have greater accuracy (i.e., the ability to reproduce an actual quantity), precision (ability to reproduce a quantity under different conditions), and capability (ability to represent smaller or larger quantities) than is possible, for example, by estimating the month from the season. Seasonal variability entails that the estimated annual time lacks accuracy and precision (however undeniable its practicality). By comparison, estimating the month from the stars is independent of seasonal variation and constitutes an improvement in accuracy but not in precision (because it can be affected by changes in viewpoint or visibility). Material techniques (e.g., knotting strings to count lunar appearances) have the potential to yield accuracy, precision, and capability (for example, counting higher quantities of moons), but entail some form of material externalization and perhaps constancy of observational position as well.

In the current sample, timekeeping transitioned from estimations of natural phenomena (e.g., the growth of Cyttaria darwinii, a fungus the Yaghan [Group 1] use as an indication of annual time; see Guisinde, 1931) to the use of manufactured artifacts (e.g., the wooden board with small holes and movable pegs the Aleut [Group 3] use to designate days; this device was possibly adopted from the Russian culture; see Innokentiu, 1840), consistent with the greater availability of material devices and the increased capability of numeration systems. This is the transition from an associational integration with the environment to a cognitively organized understanding of the environment, and it is analogous to the one in numbers in which the use of fingers and correspondences yields to the use of manufactured objects that scaffold the transition from rudimentary to explicit concepts of quantity. Just as initial numbers were not explicit concepts, 'time' need not be explicit initially either, with quantification and material externalization enabling 'time' to become concrete, manipulable, and sharable.

When astronomical timekeeping was organized by material and numeration complexity (Table 3), three themes with implications for material scaffolding emerged. First, the use of any particular astronomical phenomenon or strategy for timekeeping was initially constrained in its accuracy, precision, and capability, with the use of material externalization enabling transcendence of the constraints. Second, material externalization facilitated the apprehension and use of astronomical patterns for timekeeping, with timekeeping accuracy, precision, and capability improving with greater material complexity as a function of increased social investment and organization. Third, as material and numeration complexity increased, the concept 'time' became more explicit as something that could be quantified, with material devices and numbers as a cognitive technology enabling its quantification. These themes were consistent with the idea that cultural astronomy enables timekeeping, first by recognizing and interpreting correspondences between natural phenomena and then by developing techniques for material externalization that enrich, as numeration systems appear to, under the weight of increasing material complexity, investment of social resources, and geographic stability (Hayden \& Villeneuve). 
Table 3. Changes in Timekeeping with Increased Material and Numeration Complexity for 29 Modern Hunter-Gatherer Societies.

\begin{tabular}{lcccccc}
\hline & \multicolumn{3}{c}{ Percentage of Cultures with } & & \\
\cline { 2 - 3 } Timekeeping Practice ${ }^{1}$ & & \\
\cline { 2 - 4 } Timekeeping Practice & Group 1 & Group 2 & Group 3 & $\varphi^{2}$ & Trend \\
\hline Height estimation (sun, moon, stars) for time & $86 \%$ & $56 \%$ & $38 \%$ & .20 & Decreasing \\
\hline Use of material devices to keep time & $0 \%$ & $44 \%$ & $69 \%$ & .38 & \\
Human age estimated or counted & $0 \%$ & $11 \%$ & $31 \%$ & .29 & \\
Time divided into epochs & $0 \%$ & $11 \%$ & $23 \%$ & .24 & Increasing \\
Use of solstices for annual time & $0 \%$ & $56 \%$ & $54 \%^{3}$ & .35 & \\
Lunar cycles counted for timekeeping & $14 \%$ & $56 \%$ & $77 \%$ & .29 & \\
Awareness of solar-lunar cycle mismatch & $0 \%$ & $11 \%$ & $23 \%$ & .24 & \\
\hline Fingers used for counting & $71 \%$ & $67 \%$ & $62 \%$ & .04 & \\
Myths about the sun, moon, and stars & $86 \%$ & $89 \%$ & $85 \%$ & .02 & Constant \\
Seasons used for annual time & $86 \%$ & $89 \%$ & $85 \%$ & .02 & \\
Moon-menses relation & $57 \%$ & $56 \%$ & $54 \%$ & .02 & \\
\hline
\end{tabular}

Notes. ${ }^{1}$ Societies were rated dichotomously ( 0 , No practice noted, or 1 , Practice noted). Ratings of ' 0 ' were awarded under either of two conditions: (1) There were HRAF data specifically commenting on a society not employing a particular practice or (2) There were no HRAF data regarding a society's employment of a particular practice. This is similar to the logic used by Divale (1999) in using HRAF data to rate food storage practices; he noted that condition (2) "seemed reasonable because food storage is a low-inference variable, which would be fairly obvious to the ethnographer if it were present and important enough to be reported" (p. 346). Group percentages were then calculated from the sum of ' 1 ' ratings divided by the total number of societies in that category. A percentage change (delta) greater than $10 \%$ was interpreted as indicating an increase or decrease. ${ }^{2} \mathrm{Phi}(\varphi)$ correlations, which measure the strength of the relationship between dichotomous variables, were performed, and the resultant values are interpreted on the following scale: negligible relationship, $\varphi<.10$; weak, $\varphi=.10$ to $\varphi<.20$; moderate, $\varphi=.20$ to $\varphi<.40$; relatively strong, $\varphi=.40$ to $\varphi<.60$; strong, $\varphi=.60$ to $\varphi<.80$; and very strong, $\varphi=.80$ to $\varphi<1.00$; see Coolidge, 2000; Glass \& Hopkins, 1996; Rea \& Parker, 2005). ${ }^{3}$ An increase was noted with the transition from simple to complex material culture; no further increase was noted with the transition from early- to later-stage numeration systems.

\section{Cultural Astronomy and Complexity in Material Culture and Numeration Systems}

There were 29 modern hunter-gatherer societies for whom there were sufficient data to characterize material complexity (from Hayden \& Villeneuve, 2011), numeration system (as suggested by Menninger, 1992), and cultural astronomy (e.g., tracking solstices, counting lunar cycles, or estimating the height of stellar constellations) (Table 1 lists the societies considered in the analyses of both numbers and time and their geographic distribution; Table 3 lists the categories and percentages yielded by the conjunction of material complexity, number-term emergence, and cultural astronomy). For each of the 29 societies, the eHRAF database contained between one and 11 ethnographic sources (with an average of four) providing observations on cultural astronomy. From the comparison (Table 3), it appeared that timekeeping was consistent with both material simplicity and complexity and with both early- and later-stage numeration systems, a finding that suggests the subjective awareness of time (de Smedt \& de Cruz, 2011) may precede both material culture and numeration systems. However, interpretation of the data remains speculative, given the small number of societies in the sample and the limited number of ethnographic observations per society, which suggests there were gaps in what was recorded about any particular society's astronomy practices. Additionally, descriptions (e.g., solstice monitoring) were occasionally ambiguous as to whether what was being represented was a cultural practice or an outsider's knowledge; when this was the case, the observations were excluded from consideration. 
An overview of the findings. The use of relational estimation techniques decreased as material and numeration system complexity increased. Aspects of timekeeping that increased with increases in material and numeration complexity included the use of material devices to quantify time, as well as the counting of human age and moons, an awareness of the mismatch between the solar and lunar cycles, and the division of time into epochs. The use of solstices for annual time increased with material complexity (but did not increase further with the transition from early- to later-stage numbers). Three aspects of timekeeping or related beliefs remained constant despite increasing material and numeration complexity: the telling of myths about the sun, moon, and stars; the correlation of lunar cycles with menstruation, pregnancy, or women's power; and the use of seasonal phenomena to estimate annual time. Interestingly, as material and numeration complexity increased and time was increasingly understood through quantification, fingers were still used to count. Moreover, fingers were used to count time (i.e., the Yuki, Klamath, and the Maidu [all Group 3]; see Foster, 1944; Gatschet, 1890; Kroeber, 1972). For example, the Chukchi were noted as using their fingers and toes to count (Antropova \& Kuznetsova, 1964; Bogoraz-Tan, 1904-1909), and the Klamath not only counted lunar cycles with their fingers, they also named the lunar months after their fingers (Spier, 1930).

The use of relational estimation techniques decreased, while the use of material devices increased. As complexity in material culture and numeration systems increased, the use of relational estimation techniques to keep time decreased, and the use of material devices increased (Table 3). While no society in Group 1 was observed using a material device to quantify or measure time, the Aranda, Ona, and Yahgan (Group 1) estimated daily time from the height of the sun, stars, or moon, and the Aranda and Yahgan were observed estimating daily time from the movement of sunbeams (Basedow, 1925; Gusinde, 1931; Gusinde \& Schütze, 1937). Judgments of time were also made through correspondence quantification; both the Aranda and San (Group 1) calculated numbers of days from numbers of sleeps (Basedow, 1925; Silberbauer, 1981); the Semang (Group 1) so closely associated the sun with daytime that their words for 'sun' and 'day' shared linguistic form (Endicott, 1979). Use of the stellar progression for annual time involved narrative myths: For example, the Alutiiq (Group 2) began their year in August, timed by the appearance of the Pleiades (Clark, 1974), and explained the stars, moon, and sun as rewards given to a raven-child, revered because he gave their light to his people (Lantis, 1938).

As complexity in material culture and numeration systems increased, the use of material externalization for timekeeping increased. Using the stars for annual time involved pictorial representation, a form of externalized memory, which transitioned from no instances in Group 1, to one instance in Group 2 (the Tiwi represented stars as dots in body paint for ritual purposes; see Mountford, 1958), to one instance in Group 3 (a Koryaks man created a detailed map of star patterns; see Jochelson, 1905-1908). The Ojibwa (Group 2) recorded time using notches on a stick, with large notches representing a new moon and smaller notches representing the days between new moons (Densmore, 1929; the Ojibwa used a similar method of notation to record the passage of a copper medallion from one generation to the next; see Benton-Banai, 1979). The Quinault (Group 3) tied knots in cords to count lunar phases, menstrual cycles, and the amount of time between a marriage and the birth of a couple's first child (Olson, 1936). Increasing material complexity implies that a society is making a larger investment of social time and expertise and that it is possibly transitioning toward geographic constancy or sedentarism, which supports long-term observation of astronomical phenomena. Expertise was suggested by the old age of the men who watched sunrises or tracked solstices for the Aleut and Quinault (both Group 3; see Hrdlicka, 1945; Olson, 1936), and greater sedentarism was suggested by the construction of sweathouses used by the Yurok (Group 2) for observations of the sky (Buckley, 1982). 
Estimating or counting human age increased, and so did dividing time into epochs. As material and numeration complexity increased, so did the likelihood of counting human age. The Andamanese (Group 1) had "no means of counting, and no words to express gradations of time or size... They take no interest in the passing of years, and have no idea of their own age" (Cipriani \& Tayler, 1966). In comparison, Groups 2 and 3 were more likely to estimate age in relation to known events (the Koryaks, Pomo, and Tlingit [Group 3]; see Barrett, 1952; de Laguna, 1972; Jochelson, 1905-1908) or count age by winters (the Ojibwa [Group 2] and Assiniboine [Group 3]; see Denig \& Hewitt, 1930; Grant, 1890). In at least one case, there was a social (post-contact) reason for establishing someone's age: eligibility to collect a government pension (the Tlingit [Group 3]; see de Laguna, 1972). The division of time into epochs also positively correlated with increased material and numeration complexity. For example, the Ona (Group 1) identified the past only as "many ago" (Guisinde, 1931, p. 1580), while the Chipewyan, Tlingit, and Yokuts (Group 3) identified two epochs, the long ago and the present; further, there were hints of an emerging tripartite division for the Chipewayan and Tlingit: a remote and mythic time, the present, and an intermediate epoch loosely encompassing the last few hundred years (de Laguna, 1972; Gayton, 1946; Sharp, 1994). This suggests that numbers enable the structuring time in a way that permits a society not merely to count days but to conceive of time in an overarching sense as something large that can be parsed as mythology or history. By comparison, societies lacking numbers might be limited to a few days before and after 'today', and without much structure for time beyond ‘today' might also lack myths describing a time 'before' the present. Such a description might apply to the Pirahã, who have been described as living in the present 'now' and as lacking both numbers and origin myths (Everett, 2005, 2008).

Using solstices, counting moons, and being aware of the solar-lunar mismatch increased. As complexity increased, so did using the solstices for annual timekeeping and counting moons. The likelihood of being aware of the mismatch between the annual solar cycle and the number of lunar cycles per year also increased, a possible consequence of combined solstice use and lunar counting. The solstices enable greater accuracy in annual timekeeping (McKim \& Putnam, 1993), with the winter solstice holding a particular survival interest (a harbinger of returning spring), especially to peoples in the northern hemisphere. Interest in the winter solstice as an indicator of returning spring was rather poignantly expressed by the Aleut (Group 3), who named February and March for "the last stored food" and "foregoing hunger month," respectively, with the name for March indicating that as the food ran out, relatively inedible things like thongs and skins might be consumed (Jochelson, 1933, pp. 85-86). Counting moons by material devices such as knotting strings increased (e.g., the Quinault [Group 3]; see Olson, 1936). However, 12 or 13 lunar months approximate but do not coincide exactly with the annual cycles of the sun and stars. Knowledge of the solar-lunar cycle mismatch ranged from no idea that there was one (the San [Group 1]; see Kaufmann, 1910), to awareness of the discrepancy with no perceived need to correct it (the Chukchi [Group 2]; see Sverdrup, 1938), to awareness of the discrepancy with an attempt to fill it in by inserting an extra moon somewhere (the Yakuts [Group 3]; see Sauer, 1802).

Solstices are detected by closely measuring (as opposed to estimating) shadow length or by precisely noting the furthest point on the horizon in which the sun rises or sets (Schlosser, Schmidt-Kaler, \& Milone, 1991). Both of these techniques entail relatively long-term observations (i.e., days to years) with implications for both cultural complexity and geographic constancy. In terms of cultural complexity, making solar observations on a long-term basis to increase timekeeping accuracy and precision implies a society that is investing greater time and effort in solar observations and which is likely dedicating individuals to the practice of astronomy with 
organizational strategies such as the division of labor, task specialization, leisure time, and resource sharing (Hayden \& Villeneuve, 2011). Geographically, a society inhabiting a locale continuously uses resource strategies distinct from those used by migratory or nomadic peoples, who can simply relocate once resource depletion occurs (Harris, 1927).

Some things resisted change with increased complexity. Several aspects of culture did not change with increased material and numeration complexity. These included traditions of myths about the sun, moon, and stars; the correlation of lunar cycles with rituals or taboos related to menstruation, pregnancy, or women's power; and the use of natural phenomena for annual timekeeping. Societies in all three groups performed these practices in roughly equal proportion, implying there are aspects of culture-perhaps those related to social cohesion and pragmatic survival functions - that remain relatively independent of material complexity and the reorganizing effect of cognitive technologies. Storytelling, rituals, and taboos create a powerful framework for social identity, which in turn fosters cohesion and individual identity among members of the group and acts to increase the cooperation needed to ensure the group's survival (Ochs \& Capps, 2001). For the Tehuelche (Group 2), a mythical hero gave fire to human beings, forming their social identity from being the group thus favored (Adem, 2009). For the Innu (Group 2), the Morning Star (Venus), the first dog in a sled team, and the Canadian prime minister were all called by a term meaning 'leader' or 'first man', an identity of similar social function (Henriksen, 1973). By mediating the understanding of the social and natural environments, storytelling, rituals, and taboos are cognitive technologies (de Cruz, 2008, 2012), and though there was some incorporation of quantification - for example, gestation was recognized as lasting about nine moons, rituals needed some specified number of days to accomplish their purpose-their central aspect appeared to resist the change imposed by increased complexity and the cognitive technologies of number and time.

Pragmatically, a society would not likely depend in absolute terms on materially mediated timekeeping for its resource exploitation: As explained by Hayden and Villeneuve (2011), a modern farmer does not depend on a calendar to know when to plant her crops because the past and present weather and climate are far more likely to be accurate guides, a principle extensible to hunting and gathering regardless of the presence or lack of material complexity. Seasonal variation is simply more informative, as demonstrated by the Yuki (Group 3), who named their months with words indicative of weather conditions or plant growth (Foster, 1944). This, however, is inexact timekeeping: For the Yuki, the "indicated month ... [was] not to be taken literally—it [was] simply the informant's guess of the approximate time of year” (Foster, 1944, p. 202).

The present study focused on duration as the characteristic of time most amenable to quantification through the use of numbers as a cognitive technology. A future analysis might examine the relationship between increasing complexity in culture, numbers, and conceptions of motion, direction, pace, and frame-of-reference in time. It is possible to speculate that the relative motion of, for example, the sun across the sky as it is used to estimate the current time or approximate a future time of day might give rise to experiential associations of motion, direction, pace, and structure, just as it gives rise to experiential associations of duration (e.g., numbers of sleeps), and these might transition to materially mediated concepts or cognitive technologies as experiential duration in time yields to quantification. Since there was insufficient fidelity in the eHRAF data to demonstrate whether this was the case, the question will require further research. 


\section{The Abri Blanchard Artifact in Context}

A reason offered against Marshack's (1972) interpretation of the Abri Blanchard artifact (ca. 28,000; Fig. 4) as a lunar calendar has been that analysis of the marks indicated they were made by different tools, suggesting either temporal separation in their addition or cumbersome change to the cutting tool used to create them (d'Errico, 1991). Against the former, the effective disposition of the pattern of marks across the available surface space of the artifact (d'Errico, 1991) and the use of other marks enabling the pattern to be balanced during its production (JèguesWolkiewiez, 2005) suggest planning in the execution of the artifact that weakens the idea the marks were accumulated in distinct events. Different tools used in a single production event can imply that the artifact was "conceived as a whole" (de Smedt \& de Cruz, 2011, p. 69) or that the pattern was recreated to produce a 'fair copy', a neater version that increases the organization, refinement, and apprehension of the represented information (i.e., a key distinction between externalized memory and externalized working memory).

Since the work by Jègues-Wolkiewiez (2005) offers compelling support for interpreting the artifact as a lunar calendar, it can be compared to the lunar timekeeping practices of modern hunter-gatherer societies. In the present sample, the societies who used the moon for timekeeping did so by naming, describing, depicting, or tracking lunar phases (i.e., the Ojibwa [Group 2]; see Grant, 1890) or by counting lunar appearances (the Quinault [Group 3]; see Olson, 1936). Notably, none of the societies in the sample were described as tracking or making use of the pattern of lunar movement, which is what the Blanchard artifact depicts. Reluctance to use the lunar movement for timekeeping may be a function of variability, which constrains the apprehension and usability of the movement pattern; simply, that movement is complex (i.e., the pattern takes 19 years to repeat; see Jègues-Wolkiewiez, 2005), and understanding the pattern so that it is useful (perhaps for the esoteric purposes noted by Hayden \& Villeneuve, 2011) may require both stability of observational location and material externalization strategies to a greater degree than those used by the societies in the present analysis.

The complexity of the lunar movement also suggests there may be a significance to its representation that is absent in representing star patterns: The variability inherent in the lunar movement perhaps necessitates the cognitive organization achieved by material externalization. Simply, depicting stellar patterns in order to remember them for future years represents externalized memory (i.e., a physical device used to retain and recall information and experience to enable their transmission across time), while depicting lunar movements in order to understand and use them may also represent externalized working memory (i.e., a physical device that enables the active manipulation of information to increase its organization and apprehension and to support the attainment of a goal).

The interpretive framework from modern cultural astronomy suggests that the makers of the Abri Blanchard artifact represented the lunar movement beyond what is needed to use the moon for monthly or annual timekeeping, particularly when the pattern so exactingly recorded would not recur for another 19 years (Jègues-Wolkiewiez, 2005). The complexity inherent in the pattern of lunar movements suggests that material externalization was a strategy for organizing and reducing that complexity in order to apprehend the pattern, in addition to recording and recalling it across significant spans of time. Beyond organizing and reducing complexity, a key aspect of the Abri Blanchard notations is their effective use of surface space, suggesting familiarity with the number of items and their approximate disposition (in comparison, some of the notations of the Taï plaque appear compressed, suggesting a notation process that unexpectedly continued beyond 
the intended accumulation; see d'Errico, 1991; d'Errico et al., 2003). The effective use of surface space suggests that the Abri Blanchard artifact is no rough draft but a fairly finished product that in turn implies a tradition of gathering and organizing information materially over spans of time much longer than the months of observation inherent in the object.

Although geographic constancy is implied by the months of observation needed to develop the artifact, development of the underlying astronomical tradition need not be so directly tied to locale and would be consistent with models postulating the origin of the so-called symbolic revolution outside of Europe (e.g., d'Errico et al., 2003; McBrearty \& Brooks, 2000). The complexity of the artifact also suggests the development of material culture and quantification to the extent that the outright absence of any language seems unlikely; questions of material complexity, quantification vocabulary, and numeration systems for a society capable of producing such an artifact are more appropriately ones of "how much" rather than "if." As suggested by the changes related to material and numeration complexity (Table 3), it seems likely the society producing the Abri Blanchard artifact had decreased its use of relational estimations for timekeeping in favor of using material externalization and cognitive technologies. The material culture and social organization needed to support dedicated astronomers making detailed, longterm observations and material artifacts suggest an Aurignacian society that was geographically constant, had division of labor and expertise, and which may have possessed a later-stage numeration system with one or more base numbers and the ability to indicate higher quantities with material devices and lexicalization rules. Finally, the lunar timekeeping implied by the Abri Blanchard artifact suggests that the society creating it had transitioned from naming, mythic narration, and pictorial depictions of astronomical phenomena to material externalization (i.e., especially externalized working memory, an interaction between mind and material culture that is quite modern) and the use of cognitive technologies (i.e., numbers and time).

The cross-cultural data on which this analysis were based were insufficiently granular to be able to draw conclusions of the specific timeline, environmental challenges, or social conditions in which any particular society experienced an 'aha' moment that created numbers from material scaffolds or applied numbers to structuring time. By extension, this analysis cannot determine either when or why this occurred in prehistoric societies, though presumably there was a point at which Homo sapiens' unique neural substrates for numerosity, detailed vision, and fine motor control of fingers and objects developed sufficiently to enable the recognition of manipulated objects as instantiated number concepts. However, what these results suggest is that number systems do not develop without material complexity, that timekeeping beliefs and behaviors incorporate quantification when numbers are available, and that certain kinds of devices can assist and are perhaps indexical of the practice of quantification. While extending this analysis to prehistoric groups assumes a cognitive and cultural uniformitarianism with decreased utility the farther back in time one goes, the process of developing and using numbers necessarily started somewhere (or it would not currently exist) and can be observed in action in modern societies (albeit at a fairly insensitive level of analysis). It is also reasonable to assume that the prehistoric antecedents of the modern process would bear marked resemblance to what they not merely preceded but gave rise to.

\section{Summary}

In Origins of the Modern Mind, Donald (1991) theorized that evidence of significant cognitive change in the transition from mythic to theoretic culture would be found in new cognitive output 
classes. These would include the shift of intentional representation from auditory to visual modes of expression, the increased use of material technology to mediate the understanding of the environment, and the emergence of analytic and symbolic thought structures. Intentional visual representation would be demonstrated by visuographic invention, first in self-adornment methods such as the use of body painting, then as two- or three-dimensional depictions of actual objects (Donald). Technological mediation would be exemplified by measurement techniques, formal quantification strategies, and the externalization of memory in material forms (Donald). Finally, the emergence of analytic thought would be demonstrated by using external media not merely for passively recording information but also to represent and organize thought expressed in symbolic notation-not just externalized memory but externalized working memory, which frees up cognition for other purposes (Donald; Malafouris, 2012). Donald's description broadly characterizes the differences that emerged in the present analysis with increased complexity in material culture, numeration systems, and timekeeping, and it arguably applies to the cultures creating the Blombos beads, Abri Blanchard and Cellier artifacts, and Taï plaque as well.

In Homo sapiens, numerosity and its close relationship with the ability to manipulate fingers and objects with dexterity may provide an innate cognitive basis for the expression of number concepts as material culture. Material culture, the associated social value of material possessions, and the investment of resources, in turn, appear to scaffold the development of greater explicitness, capability, and complexity in the ability to quantify, and the use of numbers as a cognitive technology appears to structure time as a quantified construct. Increased complexity in material culture and numeration systems was consistent with an increased use of material devices, solstices, and quantification for timekeeping; a decreased reliance on estimating contextual relations from natural phenomena; and constancy in social-pragmatic realms. This pattern suggested societies were investing in greater division of labor and expertise and transitioning toward greater geographic constancy and sedentarism. Finally, the compatibility of astronomical timekeeping with both simple and complex material culture and both early- and later-stage numeration systems suggested that timekeeping originates in abilities for detecting and understanding contextual relations among natural phenomena and transitions to strategies of material mediation and cognitive technologies as enabled by greater complexity in material culture and social organization. The framework developed from comparative cultures used to interpret the Blombos beads, Abri Blanchard and Cellier artifacts, and Taï plaque suggested that the societies who manufactured the artifacts had complex material culture, later-stage numeration systems, and quantitatively structured concepts of time.

\section{Acknowledgements}

I am grateful to Dr. Tom Wynn, Dr. Frederick L. Coolidge, and Dr. Rex Welshon for closely reading several drafts of the manuscript and offering many helpful suggestions and criticisms.

\section{References}

Adem, T. A. (2009). Culture summary: Tehuelche. New Haven, CT: Human Relations Area Files (HRAF). Aginsky, B. W. (1939). Population control in the Shanel (Pomo) tribe. Albany, NY: American Sociological Association. 
Agrillo, C., Dadda, M., \& Bisazza, A. (2007). Quantity discrimination in female mosquitofish. Animal Cognition, 10, 63-70.

Alexander, F. (1949). A medical survey of the Aleutian Islands. Boston: Massachusetts Medical Society.

Anderson, M. (1978). Saami ethnoecology: Resource management in Norwegian Lapland. Ann Arbor, MI: University Microfilms International.

Andres, M., Di Luca, S., \& Pesenti, M. (2008). Finger counting: The missing tool? Behavioral and Brain Sciences, 31, 642-643.

Ansari, D. (2008). Effects of development and enculturation on number representation in the brain. Nature Reviews, 9, 278-291.

Ansari, D., Garcia, N., Lucas, E., Hamon, K., \& Dhital, B. (2005). Neural correlates of symbolic number processing in children and adults. Neuroreport, 16, 1769-1773.

Antropova, V. V., \& Kuznetsova, V. G. (1964). The Chukchi. Chicago: University of Chicago Press.

Ardila, A. (2010). On the evolution of calculation abilities. Frontiers in Evolutionary Neuroscience, 2, 1-7.

Barrett, S. A. (1952). Material aspects of Pomo culture (Vol. 2). Milwaukee, WI: Board of Trustees.

Basedow, H. (1925). The Australian aboriginal. Adelaide: F. W. Preece and Sons.

Benton-Banai, E. (1979). The Mishomis book: The voice of the Ojibway. St. Paul, MN: Indian Country Press.

Bernatzik, H. A., \& Ogilvie, V. (1938). Overland with the nomad Lapps. New York: Robert M. McBridge \& Co.

Bogoraz-Tan, V. G. (1904-1909). The Chukchee. New York: Brill.

Boroditsky, L. (2000). Metaphoric structuring: understanding time through spatial metaphors. Cognition, 75, 1-28.

Buckley, T. C. T. (1982). Menstruation and the power of Yurok women: Methods in cultural reconstruction. Washington, DC: American Anthropological Association.

Burr, D. C., Turi, M., \& Anobile, G. (2010). Subitizing but not estimation of numerosity requires attentional resources. Journal of Vision, 10, 1-10.

Cantlon, J. F., \& Brannon, E. (2006). Shared system for ordering small and large numbers in monkeys and humans. Psychological Science, 17, 401-406.

Cantlon, J. F., Brannon, E. M., Carter, E. J., \& Pelphrey, K. A. (2006). Functional imaging of numerical processing in adults and four-year-old children. PLoS Biology, 4, 844-854.

Cantlon, J., Platt, M., \& Brannon, E. (2008). Beyond the number domain. Trends in Cognitive Sciences, 30, 1-9.

Carey, S. (2009). The origin of concepts. Oxford: Oxford University Press.

Carreiras, M., Seghier, M. L., Baquero, S., Estévez, A., Lozano, A., Devlin, J. T. ... Price, C. J. (2009). An anatomical signature for literacy. Nature, 461, 983-986.

Casasanto, D., \& Boroditsky, L. (2008). Time in the mind: Using space to think about time. Cognition, 106, 579-593.

Cavanagh, P., \& Leclerc, Y. G. (1989). Shape from shadows. Journal of Experimental Psychology, Human Perception and Performance, 15, 3-27.

Chick, G. (1997). Cultural complexity: The concept and its measurement. Cross-Cultural Research, 31, 275-307.

Cipriani, L. C., \& Tayler, D. (1966). The Andaman islanders. New York: Frederick A. Praeger, Inc.

Clark, A. (1997). Being there: Putting brain, body, and world together again. Boston: MIT Press.

Clark, D. W. (1974). Koniag prehistory: Archaeological investigations at late prehistoric sites on Kodiak Island, Alaska. Stuttgart: W. Kohlhammer.

Coolidge, F. L. (2000). Statistics: A gentle introduction ( $2^{\text {nd }}$ ed.). London: SAGE.

Coolidge, F. L., \& Overmann, K. A. (2012). Numerosity, abstraction, and the emergence of symbolic thinking. Current Anthropology, 53, 204-225. 
Conneller, C. (2011). An archaeology of materials: Substantial transformations in early prehistoric Europe. New York: Routledge.

Crollen, V., Seron, X., \& Noël, M.-P. (2011). Is finger-counting necessary for the development of arithmetic abilities? Frontiers in Psychology, 2, 1-3.

Culham, J. C., \& Kanwisher, N. G. (2001). Neuroimaging of cognitive functions in human parietal cortex. Current Opinion in Neurobiology, 11, 157-163.

d'Errico, F. (1991). Microscopic and statistical criteria for the identification of prehistoric systems of notation. Rock Art Research, 8, 83-93.

d'Errico, F. (1998). Palaeolithic origins of artificial memory systems: An evolutionary perspective. In C. Renfrew \& C. Scarre (eds), Cognition and material culture: The archaeology of symbolic storage (pp. 19-50). Cambridge: McDonald Institute for Archaeological Research.

d'Errico, F. (2001). Memories out of mind: The archaeology of the oldest artificial memory systems. In A. Nowell (ed.), In the mind's eye: Multidisciplinary approaches to the evolution of human cognition (pp. 33-49). Archaeological Series 13. Ann Arbor, MI: International Monographs in Prehistory.

d’Errico, F., Henshilwood, C., Lawson, G., Vanhaeren, M., Tillier, A.-M., Soressi, M., ... Julien, M. (2003). Archaeological evidence for the emergence of language, symbolism, and music-An alternative multidisciplinary perspective. Journal of World Prehistory, 17, 1-70.

d'Errico, F., Henshilwood, C., Vanhaeren, M., \& van Niekerk, K. (2005). Nassarius kraussianus shell beads from Blombos Cave: Evidence for symbolic behaviour in the Middle Stone Age. Journal of Human Evolution, 48, 3-24.

Davidson, I., \& Noble, W. (1989). The archaeology of perception: Traces of depiction and language. Current Anthropology, 30, 125-155.

de Cruz, H. (2004). Why humans can count large quantities accurately. Philosophica, 74, 63-83.

de Cruz, H. (2008). An extended mind perspective on natural number representation. Philosophical Psychology, 21, 475-490.

de Cruz, H. (2012). Are numbers special? Cognitive technologies, material culture and deliberate practice. Current Anthropology, 53, 204-225.

de Laguna, F. (1972). Under Mount Saint Elias: The history and culture of the Yakutat Tlingit. Washington, DC: Smithsonian Institution Press.

de Smedt, J, and de Cruz, H. (2011). The role of material culture in human time representation: Calendrical systems as extensions of mental time travel. Adaptive Behavior, 19, 63-76.

Dehaene, S., \& Cohen, L. (2007). Cultural recycling of cortical maps. Neuron, 56, 384-398.

Dehaene, S., Dehaene-Lambertz, G., \& Cohen, L. (1998). Abstract representations of numbers in the animal and human brain. Trends in Neurosciences, 21, 355-361.

Denig, E. T., Hewitt, J. N. B. (1930). The Indian tribes of the upper Missouri. Washington, DC: Government Printing Office.

Densmore, F. (1929). Chippewa customs. Washington, DC: U.S. Government Printing Office.

Diester, I., \& Nieder, A. (2008). Complementary contributions of prefrontal neuron classes in abstract numerical categorization. The Journal of Neuroscience, 28, 7737-7747.

Divale, W. (1999). Climatic instability, food storage, and the development of numerical counting: A crosscultural study. Cross-Cultural Research, 33, 341-368.

Domahs, F., Moeller, K., Huber, S., Willmes, K., \& Nuerk, H.-C. (2010). Embodied numerosity: Implicit handbased representations influence symbolic number processing across cultures. Cognition, 116, 251-266.

Donald, M. (1991). The origins of the modern mind: Three stages in the evolution of culture and cognition. Cambridge, MA: Harvard University Press.

Dowden, B. (2011). Time. Internet Encyclopedia of Philosophy. Retrieved from www.iep.utm.edu/time/ 
Emmons, G. T., \& de Laguna, F. (1991). The Tlingit Indians. Seattle: University of Washington Press.

Endicott, K. M. (1979). Batek Negrito religion: The world-view and rituals of a hunting and gathering people of Peninsular Malaysia. Oxford: Oxford University Press.

Everett, D. L. (2005). Cultural constraints on grammar and cognition in Pirahã: Another look at the design features of human language. Current Anthropology, 46, 621-646.

Everett, D. L. (2008). Don't sleep, there are snakes: Life and language in the Amazonian jungle. New York: Vintage Departures.

Feigenson, L., Dehaene, S., \& Spelke, E. (2004). Core systems of number. Trends in Cognitive Sciences, 8, 307-314.

Fias, W., Lammertyn, J., Caessens, B., \& Orban, G. A. (2007). Processing of abstract ordinal knowledge in the horizontal segment of the intraparietal sulcus. The Journal of Neuroscience, 27, 8952-8956.

Foster, G. M. (1944). A summary of Yuki culture. Berkeley: University of California Press.

Frank, M. C., Everett, D. L., Fedorenko, E., \& Gibson, E. (2008). Number as a cognitive technology: Evidence from Pirahã language and cognition. Cognition, 108, 819-824.

Gatschet, A. S. (1890). The Klamath Indians of Southwestern Oregon. Washington, DC: Government Printing Office.

Gayton, A. H. (1946). Culture-environment integration. Albuquerque, NM: University of New Mexico.

Gayton, A. H. (1948). Yokuts and western Mono ethnography: Vol. 1, Tulare Lake, Southern Valley, and Central Foothill Yokuts. Berkeley: University of California Press.

Gentner, D. (2001). Spatial metaphors in temporal reasoning. In M. Gattis (ed.), Spatial schemas and abstract thought (pp. 203-222). Cambridge, MA: MIT Press.

Glass, G. V., \& Hopkins, K. D. (1996). Statistical methods in education and psychology (3 ${ }^{\text {rd }}$ ed.). Boston: Allyn and Bacon.

Gowlett, J. (1984). Mental abilities of early man: A look at some hard evidence. In R. Foley (ed.), Hominid evolution and community ecology: Prehistoric human adaptation in biological perspective (pp. 167-192). London: Academic Press.

Grant, P. (1890). The Saulteux Indians about 1804. Quebec, CA: Imprimerie générale A. Côté et Cie.

Gusinde, M. (1931). The Fireland Indians: The Selk'nam, on the life and thought of a hunting people of the Great Island of Tierra del Fuego (Vol. 1). Mödling bei Wien: Anthropos-Bibliothek.

Gusinde, M., \& Schütze, F. (1937). The Yahgan: The life and thought of the water nomads of Cape Horn. Mödling bei Wien: Anthropos-Bibliothek.

Harris, M. (1927/2001). Cultural materialism: The struggle for a science of culture (updated ed.). Walnut Creek, CA: AltaMira Press.

Haun, D. B. M., Jordan, F. M., Vallortigara, G., \& Clayton, N. S. (2010). Origins of spatial, temporal and numerical cognition: Insights from comparative psychology. Trends in Cognitive Sciences, 14, 552-560.

Hayden, B., \& Villeneuve, S. (2011). Astronomy in the Upper Palaeolithic? Cambridge Archaeological Journal, 21, 331-355.

Hendrix, L. (1997). Making historical connections: Galton's problem and opportunity. Cross-Cultural Research, 31, 308-330.

Henriksen, G. (1972). Hunters in the barrens: The Naskapi on the edge of the White Man's world. St. John's, CA: Memorial University of Newfoundland.

Hrdlicka, A. (1945). The Aleutian and Commander Islands and their inhabitants. Philadelphia: Wistar Institute of Anatomy and Biology.

Hubbard, E. M., Piazza, M., Pinel, P., \& Dehaene, S. (2009). Numerical and spatial intuitions: A role for posterior parietal cortex? In L. Tommasi, L. Nadel, \& M. A. Peterson (eds), Cognitive biology: 
Evolutionary and developmental perspectives on mind, brain and behavior (pp. 221-246). Cambridge, MA: MIT Press.

Hunt, S., Low, J., \& Burns, K. C. (2008). Numerical competency in a food-hoarding songbird. Proceedings of the Royal Society: Biological Sciences, 275, 2373-2379.

Hurford, J. R. (1975). The linguistic theory of numerals. Cambridge: Cambridge University Press.

Hurford, J. R. (2007). The origins of meaning: Language in the light of evolution. Oxford: Oxford University Press.

Hyde, D. C., \& Spelke, S. (2011). Spatiotemporal dynamics of processing nonsymbolic number: An eventrelated potential source localization study. Human Brain Mapping. Retrieved from http://onlinelibrary.wiley.com/doi/10.1002/hbm.21352/pdf

Imbo, I., Vandierendonck, A., \& Fias, W. (2011). Passive hand movements disrupt adults' counting strategies. Frontiers in Psychology, 2, 1-5.

Imura, T., Tomonaga, M., \& Yagi, A. (2006). Processing of shadow information in chimpanzee (Pan troglodytes) and human (Homo sapiens) infants. In T. Matsuzawa, M. Tomonaga, \& M. Tanaka, M. (eds) Cognitive development in chimpanzees (pp. 305-316). Tokyo: Springer-Verlag.

Imura, T., Yamaguchi, M. K., Kanazawa, S., Shirai, N., Otsuka, Y., Tomonaga, M., ... Yagi, A. (2006). Perception of motion trajectory of object from the moving cast shadow in infants. Vision Research, 46, 652-657.

Innokenti1̌, S. (1840). Notes on the islands of the Unalaska District. B. Keen \& A. Kardinelowska (Trans.). St. Petersburg: Russian-American Company.

Itkonen, T. I., Guemati, O., \& Perez-Roman, E. (1948). The Lapps in Finland up to 1945 (Vol. 2). Helsinki: Werner Söderström Osakeyhtiö.

Jègues-Wolkiewiez, C. (2005). Aux racines de l'astronomie, ou l'ordre caché d’une oeuvre paléolithique. Antiquités Nationales, 37, 43-62.

Jochelson, W. (1905-1908). The Koryak. New York: Brill.

Jochelson, W. (1933). History, ethnology, and anthropology of the Aleut. Washington, DC: Carnegie Institution of Washington.

Kamii, C., \& Russell, K. A. (2010). The older of two trees: Young children's development of operational time. Journal for Research in Mathematics Education, 41, 6-13.

Kaufmann, H. (1910). Die $\neq$ Auin: Ein beitrag zur Buschmannforschung. Mitteilungen aus den deutchen Schutzgebieten, 23, 135-160.

Kelley, D. H., \& Milone, E. F. (2005). Exploring ancient skies: An encyclopedic survey of archaeoastronomy. New York: Springer.

Kender, J. R., \& Smith, E. M. (1987). Shape from darkness: Deriving surface information from dynamic shadows. Proceedings of the First International Conference on Computer Vision (pp. 539-546). London: IEEE Publishing.

Kersten, D., Mamassian, P., \& Knill, D. C. (1997). Moving cast shadows induce apparent motion in depth. Perception, 26, 171-192.

Kleffner, D. A., \& Ramachandran, V. S. (1992). On the perception of shape from shading. Perception \& Psychophysics, 52, 18-36.

Klein, E., Moeller, K., Willmes, K., Nuerk, H.-C., \& Domahs, F. (2011). The influence of implicit handbased representations on mental arithmetic. Frontiers in Psychology, 2, 1-7.

Knill, D. C., Mamassian, P., \& Kersten, D. (1997). Geometry of shadows. Journal of the Optical Society of America A, 14, 3216-3232. 
Krinzinger, H., Koten, J. W., Horoufchin, H., Kohn, N., Arndt, D., Sahr, K., ... Willmes, K. (2011). The role of finger representations and saccades for number processing: An fMRI study in children. Frontiers in Psychology, 2, 1-12.

Kroeber, A. L. (1972). The Huchnom and Coast Yuki. St. Clair Shores, MI: Scholarly Press.

Lantis, M. (1938). The mythology of Kodiak Island, Alaska. Boston: Houghton, Mifflin, and Co.

Latta, F. F. (1949). Handbook of Yokuts Indians. Oildale, CA: Bear State Books.

Loeb, E. M. (1926). Pomo folkways. Berkeley: University of California Press.

Maguire, E. A., Woollett, K., \& Spiers, H. J. (2006). London taxi drivers and bus drivers: A structural MRI and neuropsychological analysis. Hippocampus, 16, 1091-1101.

Malafouris, L. (2010). Grasping the concept of number: How did the sapient mind move beyond approximation? In C. Renfrew and I. Morley (eds), The archaeology of measurement: Comprehending heaven, earth and time in ancient societies (pp. 35-42). Cambridge: Cambridge University Press.

Malafouris, L. (2012). Reply to Coolidge and Overmann. Current Anthropology, 53, 204-225.

Mamassian, P. (2004). Impossible shadows and the shadow correspondence problem. Perception, 33, 1279-1290.

Mamassian, P., \& Goutcher, R. (2001). Prior knowledge on the illumination position. Cognition, 81, B1-B9.

Mamassian, P., Knill, D. C., \& Kersten, D. (1998). The perception of cast shadows. Trends in Cognitive Sciences, 2, 288-295.

Man, E. H. (1932). On the aboriginal inhabitants of the Andaman Islands. London: The Royal Anthropological Institute of Great Britain and Ireland.

Marshack, A. (1972). Cognitive aspects of Upper Paleolithic engraving. Current Anthropology, 13, 445-477.

Marshack, A. (1985). Hierarchical evolution of the human capacity: The Paleolithic evidence. $54^{\text {th }}$ James Arthur lecture on the evolution of the human brain. New York: American Museum of Natural History.

Marshack, A. (1991). The Taï Plaque and calendrical notation in the Upper Palaeolithic. Cambridge Archaeological Journal, 1, 25-61.

McBrearty, A., \& Brooks, A. (2000). The revolution that wasn't: A new interpretation of the origin of modern human behavior. Journal of Human Evolution, 39, 453-563.

McComb, K. C., Packer, C., \& Pusey, A. (1994). Roaring and numerical assessment in contests between groups of female lions, Panthera leo. Animal Behavior, 47, 379-387.

McKim, M. J., \& Putnam, C. (1993). Prehistoric astronomy in the southwest (revised ed.). Boulder, CO: Johnson.

Menninger, K. (1992). Number words and number symbols: A cultural history of numbers. P. Broneer (Trans.). New York: Dover.

Miller, E. K., Nieder, A., Freedman, D. J., \& Wallis, J. D. (2003). Neural correlates of categories and concepts. Current Opinion in Neurobiology, 13, 198-203.

Mithen, S. (1996). The prehistory of the mind: The cognitive origins of art and science. New York: Thames and Hudson.

Mountford, C. P., (1958). The Tiwi: Their art, myth, and ceremony. London: Phoenix House.

Murai, C. (2006). Early spontaneous categorization in primate infants-chimpanzees, humans, and Japanese macaques - with the familiarization-novelty preference task. In T. Matsuzawa, M. Tomonaga, \& M. Tanaka, M. (eds) Cognitive development in chimpanzees (pp. 279-304). Tokyo: Springer-Verlag.

Ochs, E., \& Capps, L. (2001). Living narrative: Creating lives in everyday storytelling. Cambridge, MA: Harvard University Press.

Olson, R. L. (1936). The Quinault Indians. Seattle: The University of Washington. 
Orban, G. A., Claeys, K., Nelissen, K., Smans, R., Sunaert, S., Todd, J. T., ... Vanduffel, W. (2006). Mapping the parietal cortex of human and non-human primates. Neuropsychologia, 44, 2647-2667.

Overmann, K. A., Wynn, T., \& Coolidge, F. L. (2011). The prehistory of number concept. Behavioral and Brain Sciences, 34, 142-144.

Owens, D., \& Hayden, B. (1997). Prehistoric rites of passage: A comparative study of transegalitarian hunter-gatherers. Journal of Anthropological Archaeology, 16, 121-161.

Pariyadath, V., Churchill, S. J., \& Eagleman, D. M. (2005). Why overlearned sequences are special: Distinct neural networks in the right hemisphere for ordinal sequences. Cognition, 98, 53-84.

Piazza, M. (2010). Neurocognitive start-up tools for symbolic number representations. Trends in Cognitive Sciences, 14, 542-551.

Pica, P., Lemer, C., Izard, V., \& Dehaene, S. (2004). Exact and approximate arithmetic in an Amazonian indigene group. Science, 306, 499-503.

Pilling, A. R. (1978). Yurok. In R. F. Heizer (ed.), Handbook of North American Indians (Vol. 8, pp. 137154). Washington, DC: Smithsonian Institution.

Quinn, P. C. (2011). Born to categorize. In U. Goswami (ed.), The Wiley-Blackwell handbook of childhood cognitive development ( $2^{\text {nd }}$ ed., pp. 129-152). Chichester, UK: Wiley-Blackwell.

Quinn, P. C., Westerlund, A., \& Nelson, C. A. Neural markers of categorization in 6-month-old infants. Psychological Science, 17, 59-66.

Ramachandran, V. S. (1988). Perception of shape from shading. Nature, 331, 163-166.

Rea, L. M., \& Parker, R. A. (2005). Designing and conducting survey research: A comprehensive guide ( $3^{\text {rd }}$ ed.). San Francisco: John Wiley \& Sons.

Rips, L. J., Bloomfield, A., \& Asmuth, J. (2008). From numerical concepts to concepts of number. Behavioral and Brain Sciences, 31, 623-642.

Rouillon, A. (2006). Au Gravettien, dans la grotte Cosquer (Marseille, Bouches-du-Rhône), l'Homme a-til compté sur ses doigts? L'anthropologie, 110, 500-509.

Sato, M., Cattaneo, L., Rizzolatti, G., \& Gallese, V. (2007). Numbers within our hands: Modulation of corticospinal excitability of hand muscles during numerical judgment. Journal of Cognitive Neuroscience, 19, 684-693.

Sauer, M. (1802). An account of a geographical and astronomical expedition to the northern parts of Russia by Commodore Joseph Billings, in the years 1785-1794. London: T. Cadell, Junior, and W. Davies.

Schaefer, J. M. (1974). Studies in cultural diffusion: Galton's problem a preview. Behavior Science Research, 9, 1-3.

Schlosser, W., Schmidt-Kaler, T., \& Milone, E. F. (1991). Challenges of astronomy: Hands-on experiments for the sky and laboratory. New York: Springer-Verlag.

Sharp, H. S. (1994). Inverted sacrifice. Tokyo: University of Tokyo Press.

Silberbauer, G. B. (1981). Hunter and habitat in the central Kalahari Desert. Cambridge: Cambridge University Press.

Spencer, B., \& Gillen, F. J. (1927). The Arunta: A study of a Stone Age people. London: Macmillan and Co..

Spier, L. (1930). Klamath ethnography. Berkeley: University of California Press.

Sterelny, K. (2010). Minds: Extended or scaffolded? Phenomenology and the Cognitive Sciences, 9, 465-481.

Sun, J. Y., \& Perona, P. (1995). Preattentive perception of elementary three-dimensional shapes. Vision Research, 36, 2515-2529.

Sverdrup, H. U. (1938). With the people of the Tundra. Oslo: Gyldendal Norsk Forlag.

Takakura, S. I., \& Harrison, J. A. (1960). The Ainu of northern Japan: A study in conquest and acculturation. Philadelphia: American Philosophical Society. 
Tang, Y., Zhang, W., Chen, K., Feng, S., Ji, Y., Shen, J., ... Liu, Y. (2006). Arithmetic processing in the brain shaped by cultures. Proceedings of the National Academy of Sciences of the United States of America, 103, 10775-10780.

Tarr, M. J., Kersten, D., \& Bülthoff, H. H. (1998). The visual recognition system might encode the effects of illumination. Vision Research, 38, 2259-2275.

Torralbo, A., Santiago, J., \& Lupiáñez, J. (2006). Flexible conceptual projection of time onto spatial frames of reference. Cognitive Science, 30, 745-757.

Turnbull, C. M. (1965). The Mbuti Pygmies: An ethnographic survey. New York: American Museum of Natural History.

Turnbull, C. M. (1983). The Mbuti Pygmies: Change and adaptation. Orlando: Harcourt Brace

Vanhaeren, M., \& d'Errico, F. (2006). Aurignacian ethno-linguistic geography of Europe revealed by personal ornaments. Journal of Archaeological Science, 33, 1105-1128.

VanMarle, K., \& Wynn, K. (2010). Tracking and quantifying objects and non-cohesive substances. Developmental Science, 14, 502-515.

Woods, A. D. (2011). The effects of lithic raw material quality on Aurignacian blade production at Abri Cellier (doctoral dissertation, University of Iowa). Retrieved from http://ir.uiowa. edu/etd/1111

Wynn, T. (1991). Tools, grammar, and the archaeology of cognition. Cambridge Archaeological Journal, 1, 191-206.

Wynn, T., Overmann, K. A., Coolidge, F. L., \& Janulis, K. (2012). Bootstrapping the modern mind. Submitted manuscript. [Published in 2017 as "Bootstrapping ordinal thinking” in T. Wynn \& F. L. Coolidge (eds), Cognitive models in Palaeolithic archaeology, Oxford University Press, pp. 197-213.]

Zamarian, L., Ischebeck, A., \& Delazer, M. (2009). Neuroscience of learning arithmetic-Evidence from brain imaging studies. Neuroscience and Biobehavioral Reviews, 33, 909-925. 